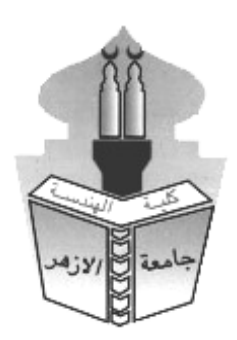

\title{
SUSTAINABLE RATING SYSTEM FOR EGYPTIAN SOCCER STADIUMS
}

\begin{abstract}
ABASTRACT
The construction of sustainable stadiums has become a global trend at present for its significant role in reducing energy and resource consumption, reducing building and operating costs, conserving the environment by reducing carbon emissions, creating a sense of space, encouraging social interaction and providing comfort, comfort and safety for users compared to traditional stadiums. In the period from 2006-2013 to 40\%, which can be increased as a result of the interest and support of the International Federation of Football (FIFA) in supporting and spreading the concept of sustainability in the field of building stadiums football starting from the events of the Cup World 2006. states are competing in the application of sustainability in stadium buildings as one of the main features of modern and future stadiums, However, Egyptian stadiums are far from achieving this concept and are still traditional in their design, construction and operation. No Egyptian stadium has ever been certified by international systems such as LEED and BREEAM, which requires a sustainable assessment guide to develop existing local stadiums and build new stadiums to become sustainable..
\end{abstract}

Nesreen Fathy Abdsallam ${ }^{1}$ and Kareem Mahrous Ali ${ }^{2}$

${ }^{1}$ Faculty of Engineering-Mataria-Helwan university

${ }^{2}$ Modern Academy for Engineering \& Technology

${ }^{1}$ Architectkareemmahrous87@gmail.com

Nesreen_fathy@msm.com

\section{Key words: Sustainable Stadiums - Rating svstem - Traditional local stadiums - Reducing energv consumption and resources - Reducing costs of building and operating - Developing existing stadiums - FIFA's interest}

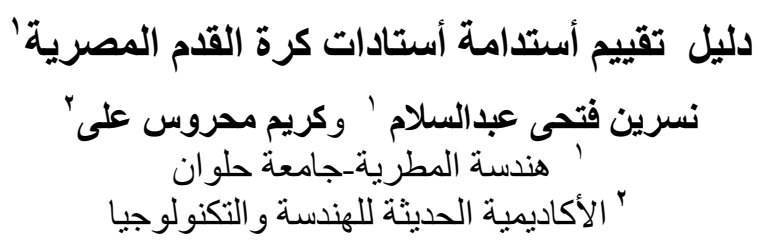

أصبح بناء الأستادات المستدامة توجها عالميا فى الوقت الحالى لدور ها الكبير فى خفض أستهلاك الطاقة والموارد

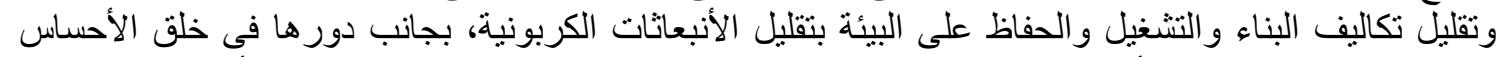

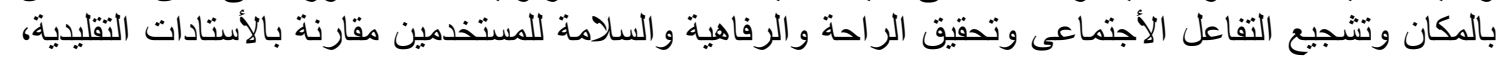

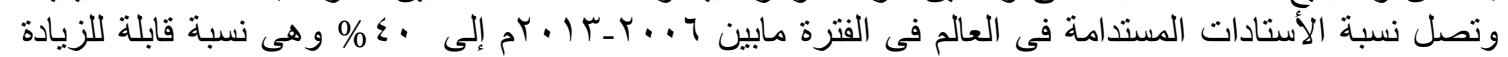

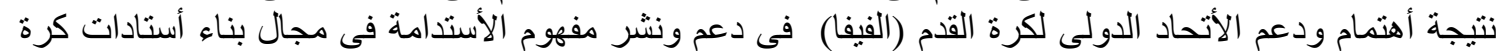

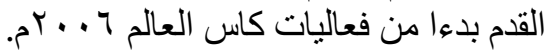
1 بحث للنشر من منطلبات الحصول على درجة الدكتور اه ،"منهج تطبيقى مستدام لإنشاء وتطوير الأستادات فى مصر". 
وتتسابق الدول فى تطبيق الأستدامة فى مبانى الأستادات كأحد السمات الأساسية للأستادات الحديثة والمستقبلية،

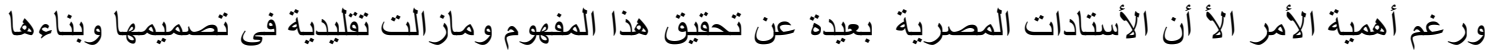

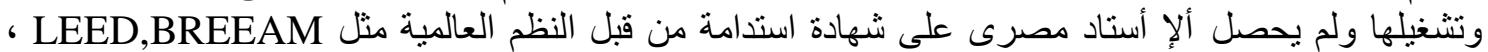
و هو مايتطلب عمل دليل تقييم أستدامة لتطوير الأستادات المحلية القائمة وبناء الأستادات الجديدة لتصبح مستدامة.

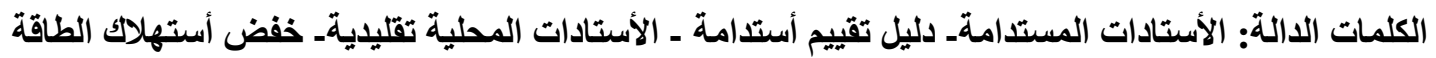

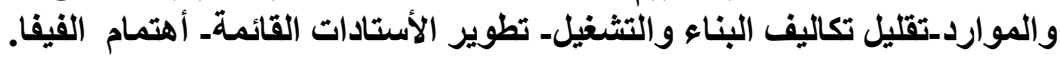

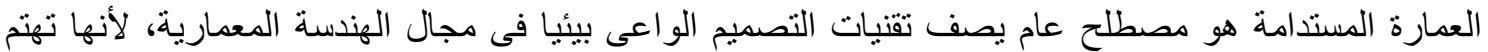

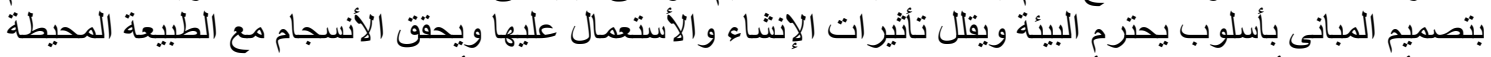

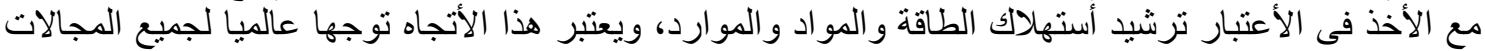
فى الوقت المعاصر لهذا يهتم المختصين مثل الأتحاد الدولى لكرة القدم( الفيفا) و الأتحاد الأوربى لكرة القئ القدم (اليويفا)

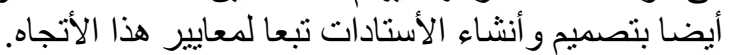

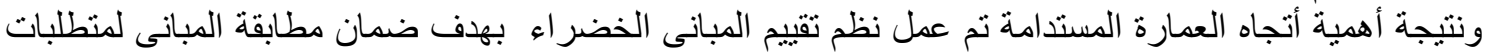

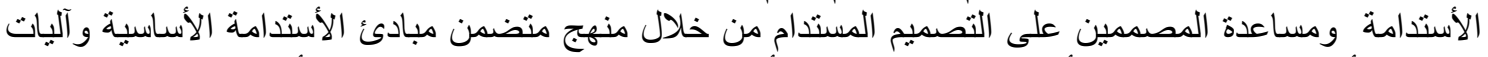

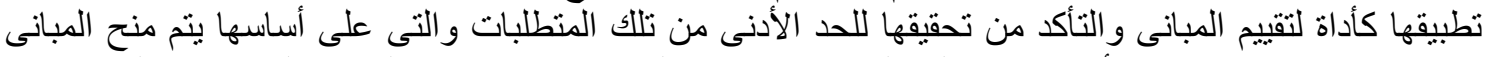

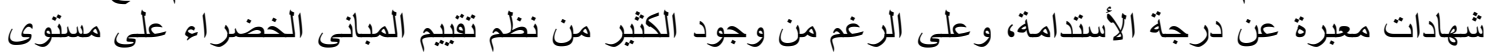

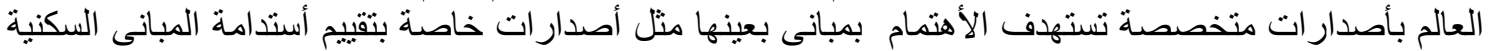

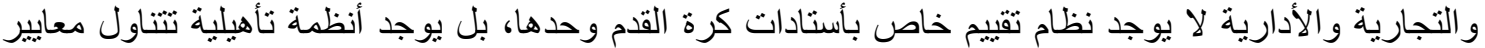

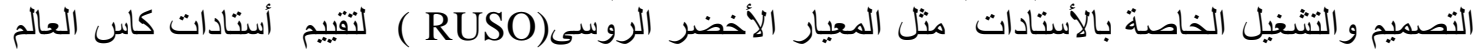

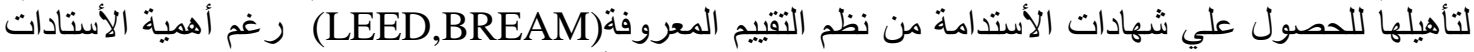

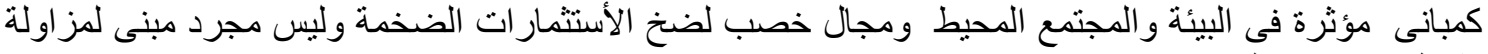
نشاط رياضى فقط.

المشكلة البحثية

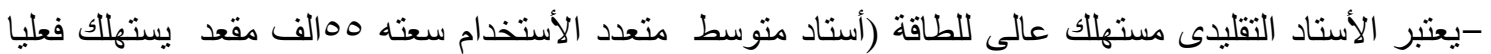

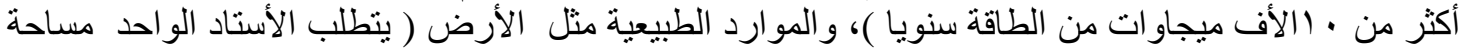

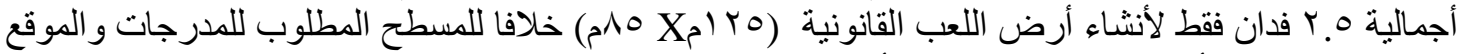

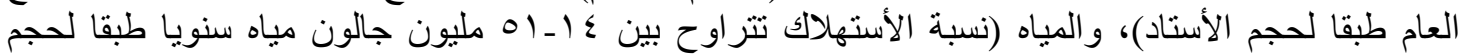

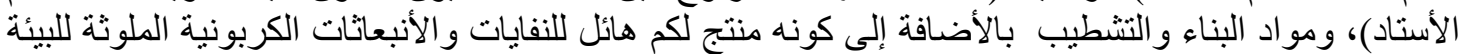

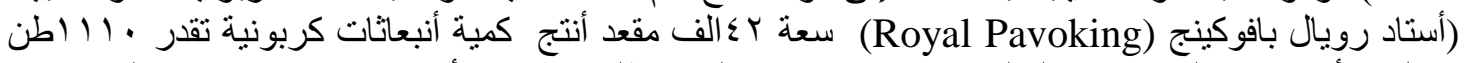

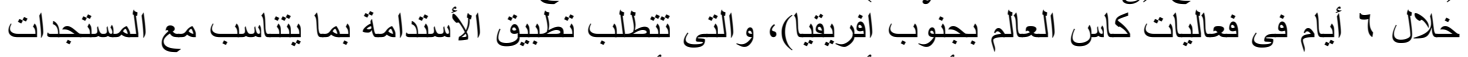

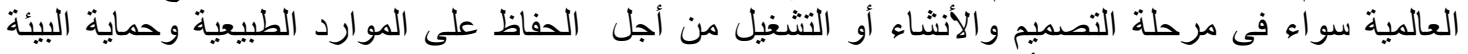

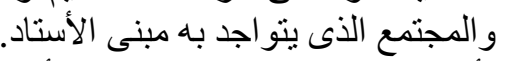

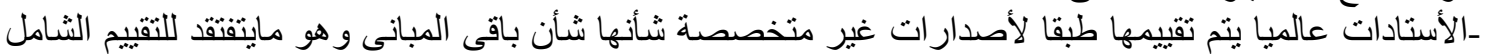

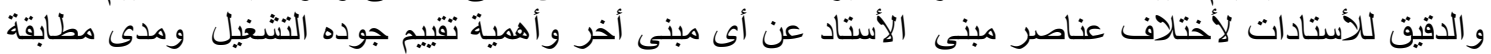

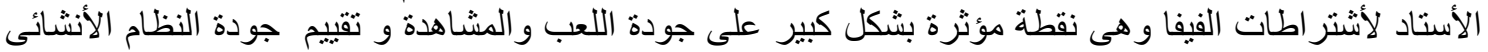

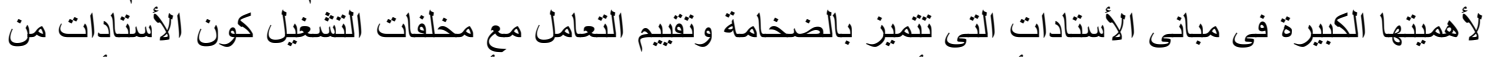

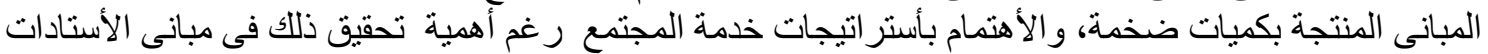

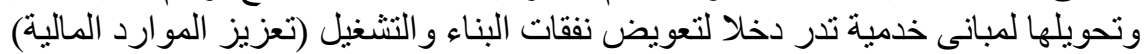

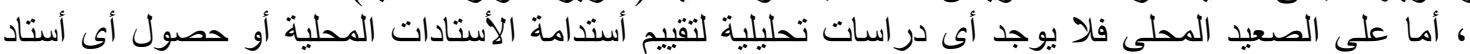

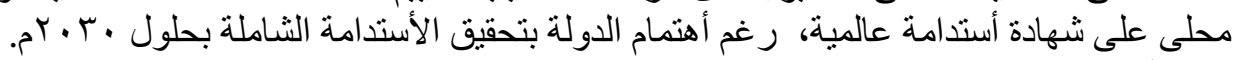

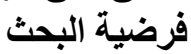

أنه من خلال الوصة الوصل إلى دليل أستدامة رياضية بمكن تحقيق التقييم الدقيق لدرجة أستدامة الأستادات المحلية

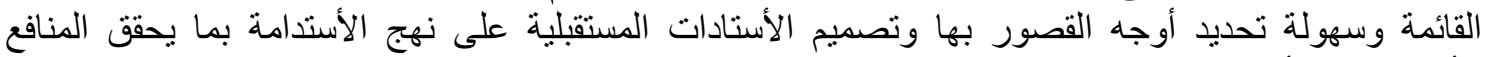
الأجتماعية و الأقتصادية و البيئية المطلوبة.

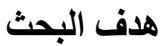
بناء دليل أستدامة متخصص فى تقييم أستدامة الأستادات المحلية القائمة والمستقبلية يلائم تطبيقه الوضع المحلى. 


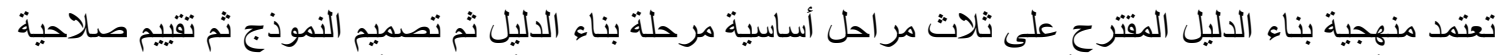

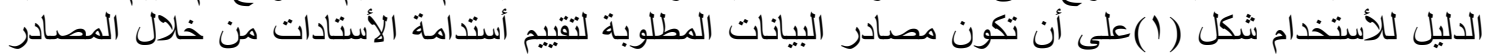

- نتائج الدر اسة النظرية و المتمنلة فى كيفية تصميم أستاد مستدام.

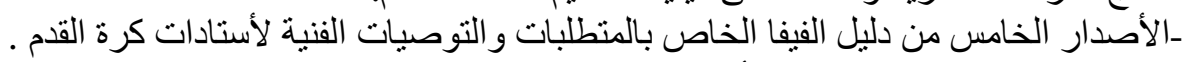

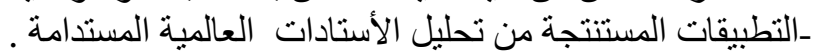

-تحليل نظم الأستدامة العالمية ومعايير الأنظمة التاهيلية ومعدلات التئنة التقييم للنظم ومدى ملائمة العناصر و تقييمها.

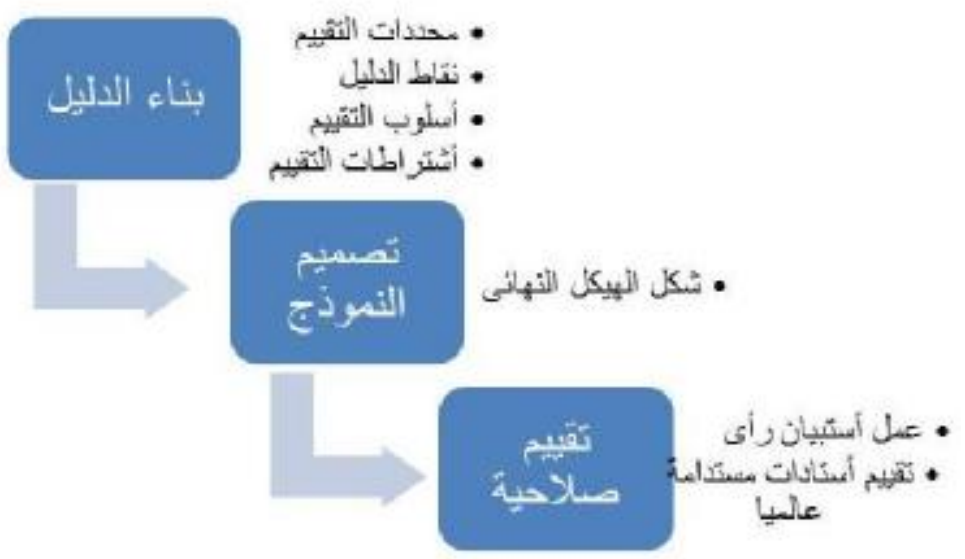

شكل( ) منهجية بناء الاليل

المصدر :الباحث

1- أولا :الدراسة النظرية: آلية تصميم أستاد مستدام

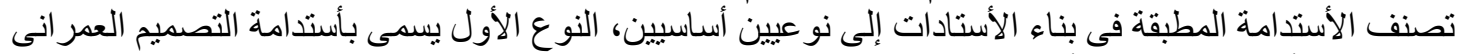

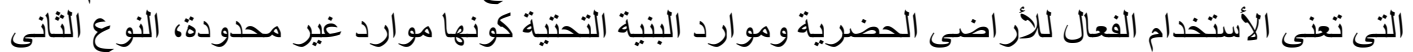

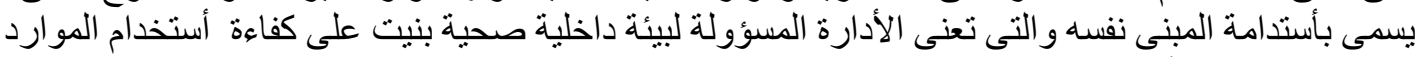

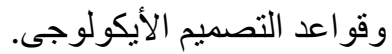

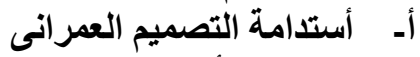

يتطلب تحقيق الأستدامة فى التصميم العمر انى لموقع الأستاد يتطلب مر اعاة المتطلبات التصميمية الخاصة بأختيار

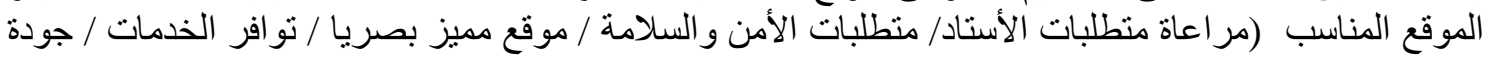

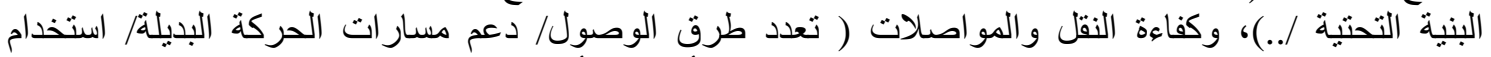

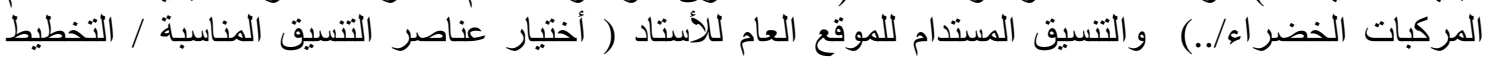

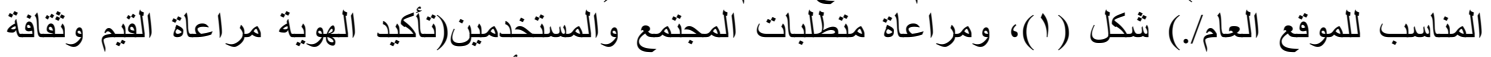
المجتمع فى التصميم شكل (Y)/مر اعاة خصائص الموقع المحيط /تعددية الأستخدام /..).

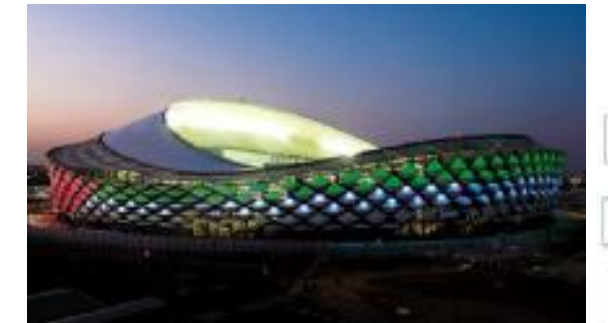

شكل(r) أقتباس فكرة الواجهة من سيقان نخيل البلح أستاد هزاع

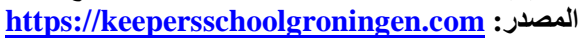

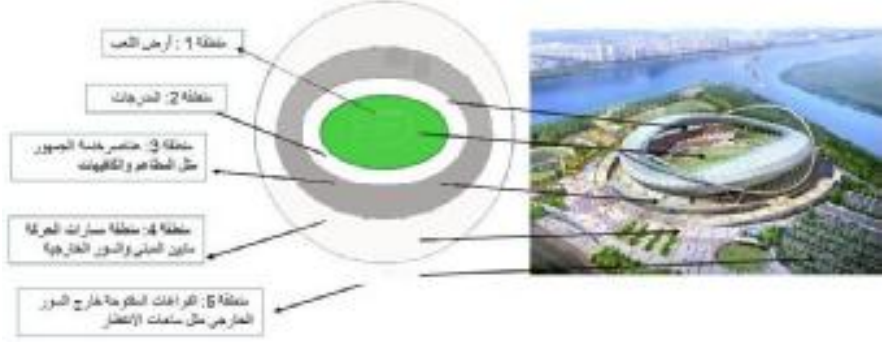

شكل( (1) ) أسكتش مدعم بمثال لتوضيح كيفيةالتخطيط المناسب للموقع العام

Geriant john, Rod Sheaard\& Ben Vickery,"Stadia,p33 ب أستذامة مبنى الأستاد

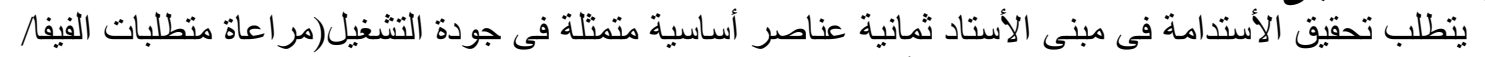

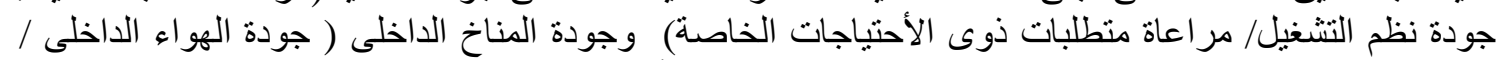

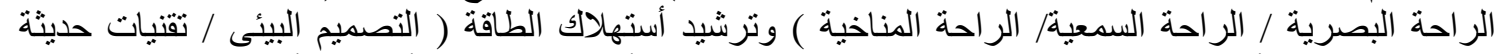

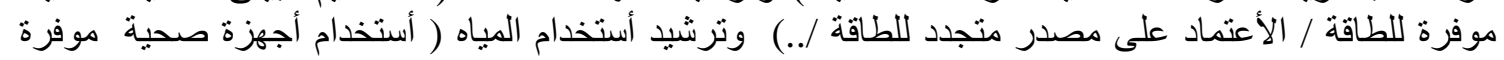


للمياه/ أستغلال مياه الأمطار / تدوير المياه الرمادية/ جودة التوصيلات الصحية /..) شكل (ب)، وترشيد أستخدام

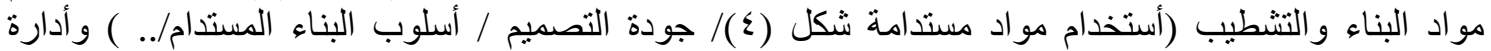
المخلفات (الحد من مخلفات التشغيل / الحد من مخلفات البناء ) والأدارة بالأضافة إلى الأبتكار.
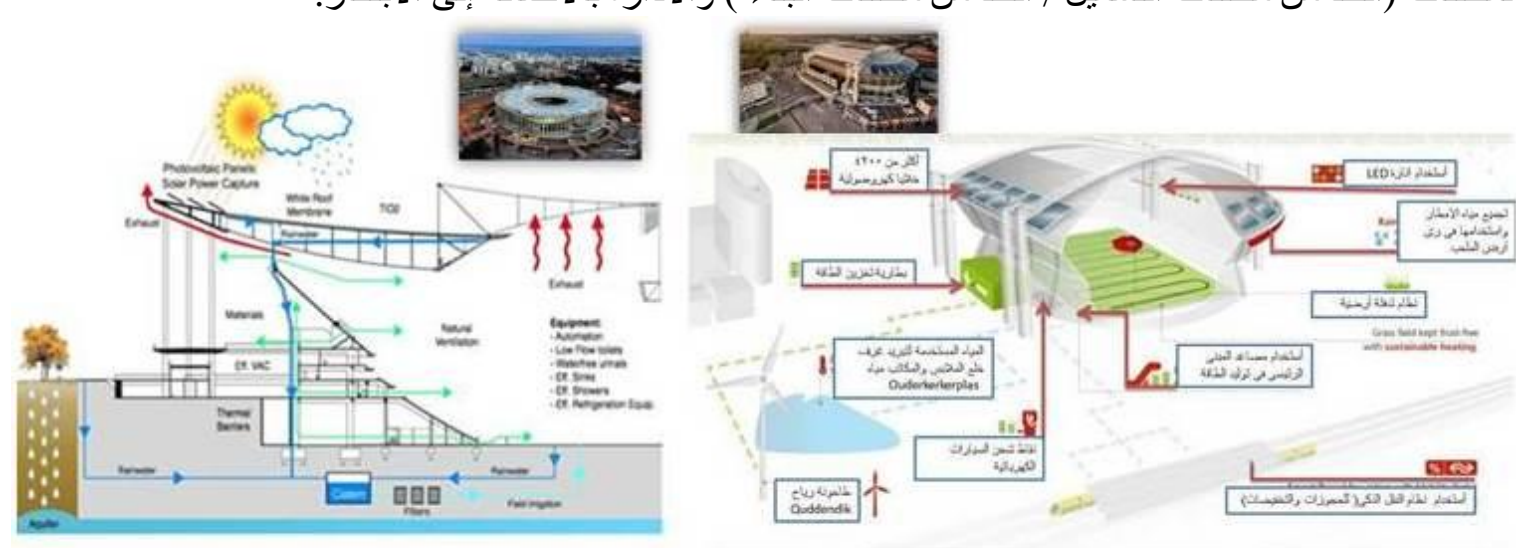

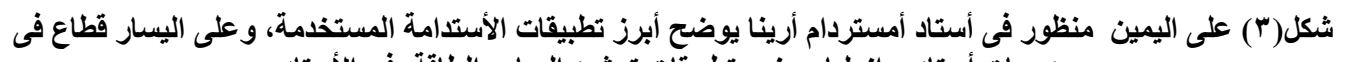
مدرجات أستاد برازيليا يوضح تطبيقات ترشيا ارئا المياه والطاقة فى الأستاد. المصدر: WWW.Archdaily.com

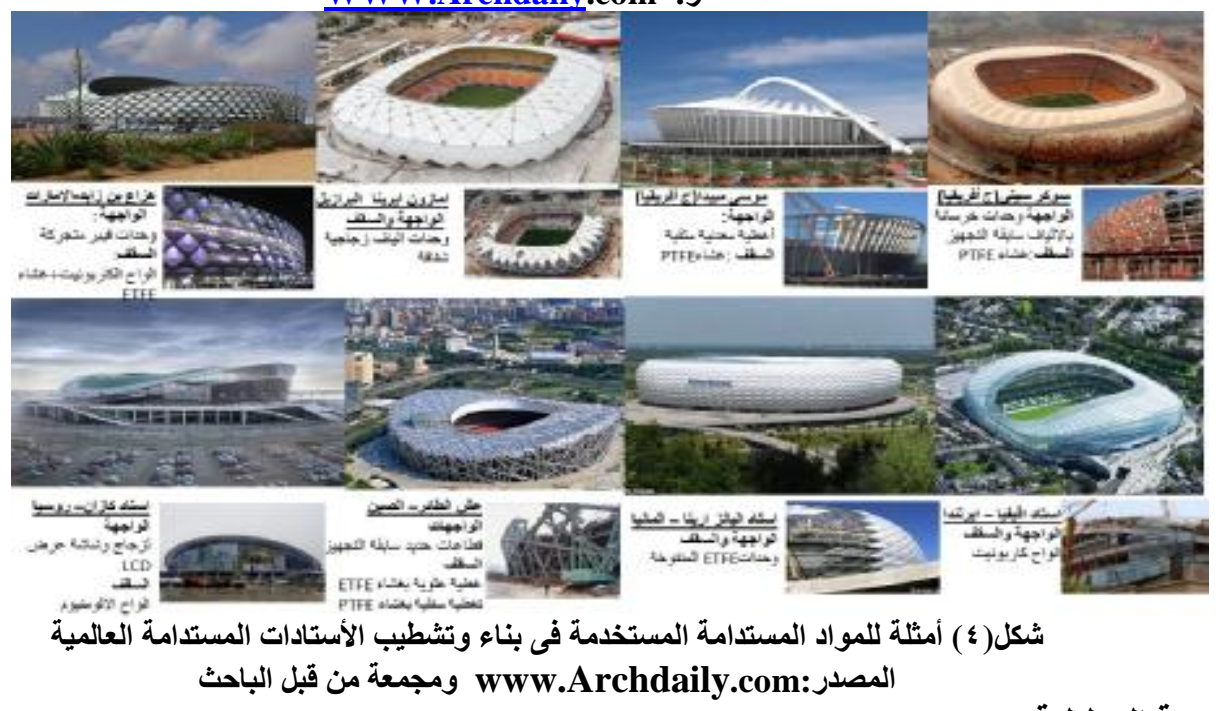

ثانيا : الارسة التحليلية أـتحليل أستاد عالمى مستدام (استاد مرسيدس بينز) شكل (0) طبقا لنتائج الدار اسة النظرية.

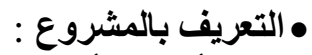

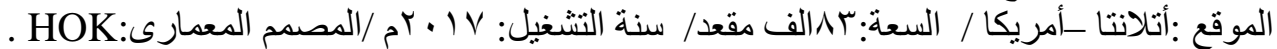

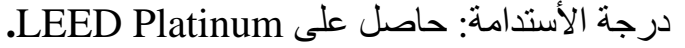

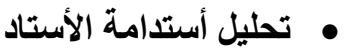
آليات تحقيق الأستدامة العمرانية شكل(7) B

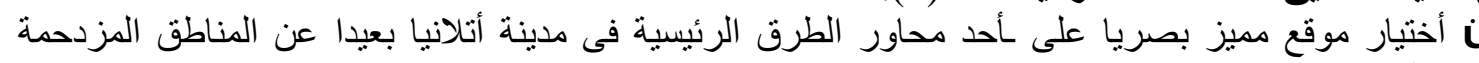

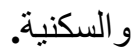
ر أختيار موقع سهل الوصول إليه بوسائل النقل المختلفة، عمل محطات شحن لعدد 1 ـ سيارة كهربائية.

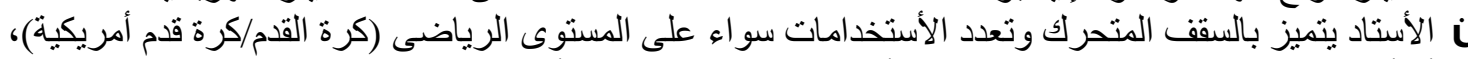

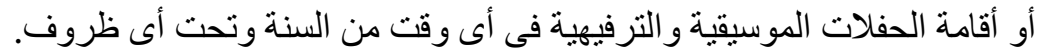
ر أمكانية تغذية شبكة الكهرباء العمومية بفائض الكهرباء المنولة لدة و الز ائدة عن أحتياجات الاستاد . 


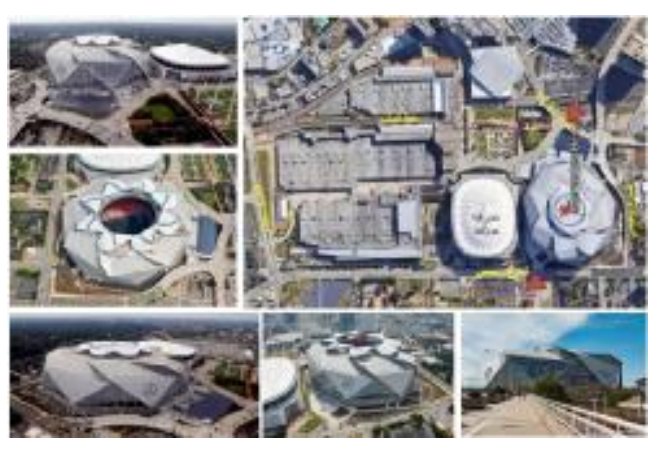

شكل(†) صور مجمعة توضح الأستدامة العمرانية المصدر:

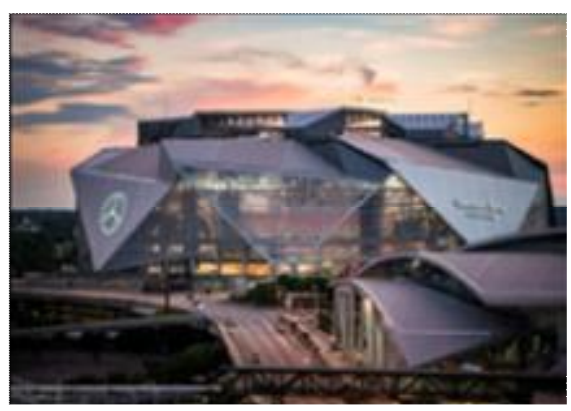

شكل(•) أستاد مرسيدس بينز ألمصدر: آليات تحقيق أستدامة المبني

د جوده التشغيل: تصميم الأستاد طبقا للأشتر اطات الأتحاد الدولى و ونتوافر فيه أحدث نظم التشغيل التى تحقق منطلبات الأمن و السلامة و الر احة و التران الترفية للمستخدمين.

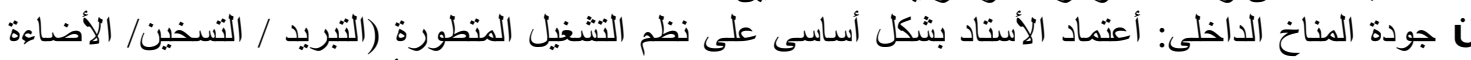

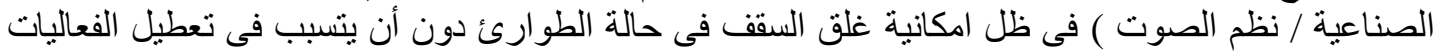

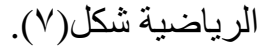

ترشيد مو اد البناء والتشطيب: أستخدام أحدث نظم تكنولوجيا فى مجال البناء مثل الحوائط الزجاجية المتحركة

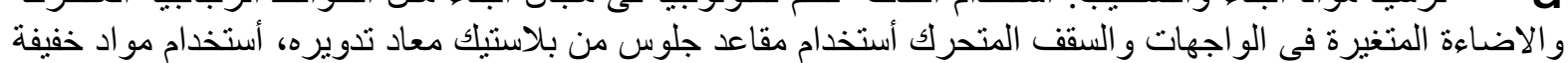

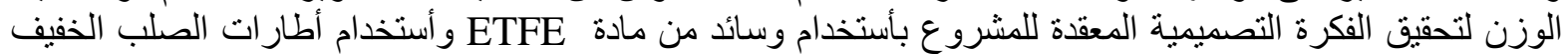

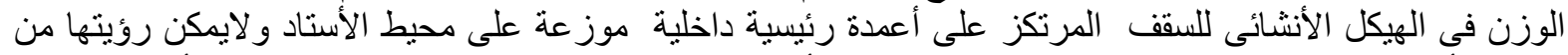

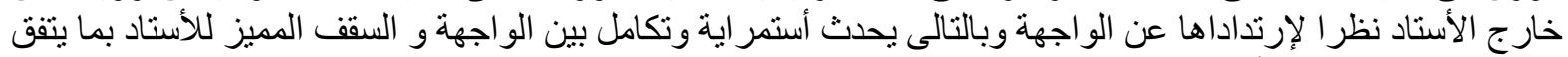
مع الفكرة التصميمية للأستاد. رترشيد أستهلاك الطاقة: تصميم الأستاد و عمل السقف متحرك يسمح بادة بالأضاءة و التهوية الطبيعة بالأضافة إلى أستخدام

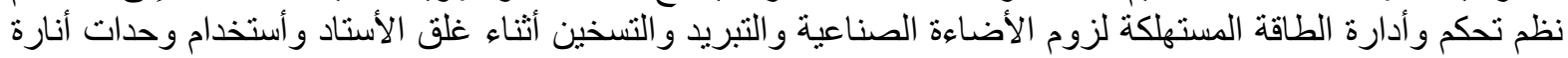

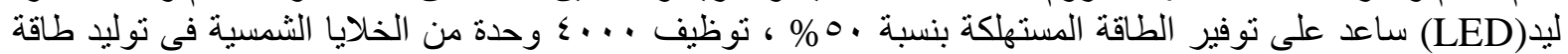

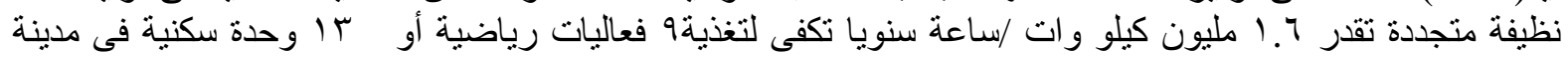
أتلانتا.

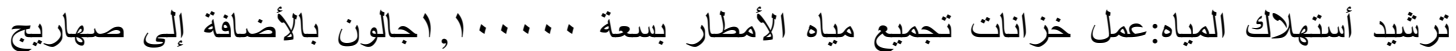

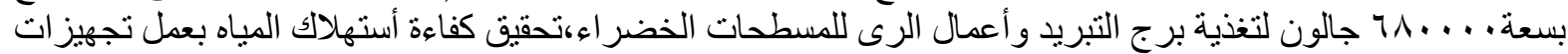

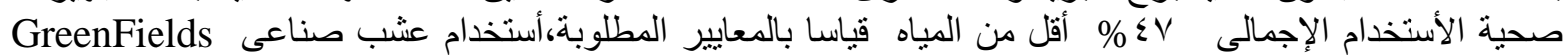
.USA's MX 3-STAR turf sys 


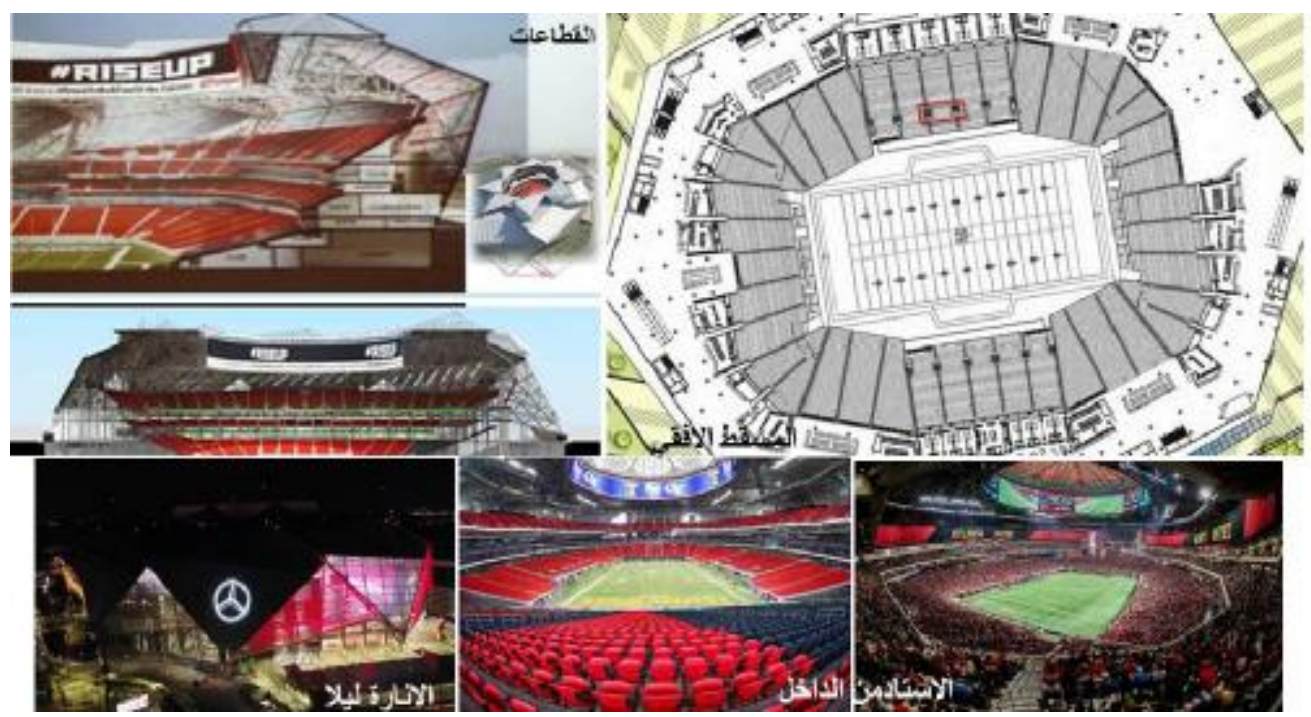

شكل(V) المسقط الأفقى وقطاعات الأستاد وصور توضح جودة التثغيل والمناخ الداخلى للأستاد المصدر:www.archdaily .com

ثانيا : الارسة التحليلية ب-مقارنة بين أهم نظم تقييم الأستدامة ونظم التأهيل

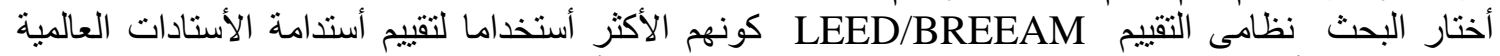

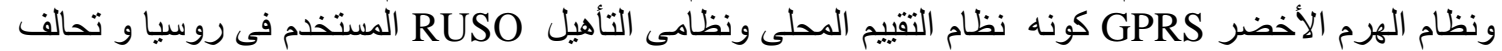
الرياضات الاخضر, GREEN SPORTS ALLIANCE و عمل مقارنة من حيث هدف كل نظام ونطاق

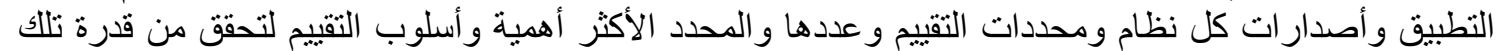

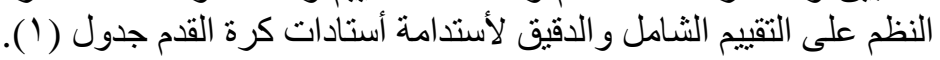

جدول (1) - (1) مقارنة النظم المختارة

\begin{tabular}{|c|c|c|c|c|c|}
\hline \multicolumn{2}{|c|}{ نظم تأهيلية } & \multicolumn{3}{|c|}{ نظم تقيمب أستدامة } & \multirow{2}{*}{ عناصر التحليل } \\
\hline GSA & RUSO & GPRS & LEED & BREEAM & \\
\hline 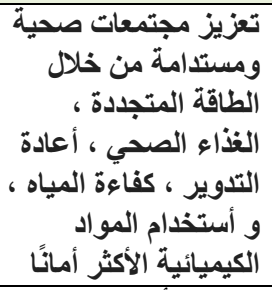 & 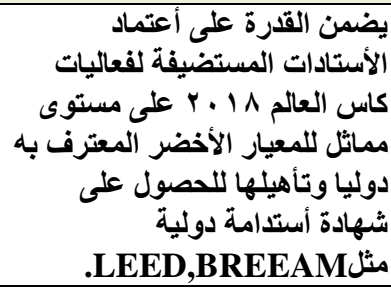 & 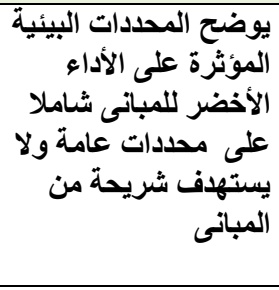 & 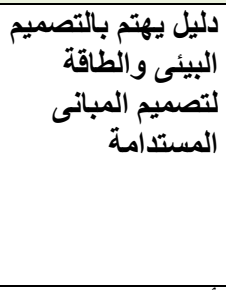 & المبين يهتم بمر احل & هاف النظام \\
\hline أمريكا & روسيا & مصر & أمريكا & المملكة المتحدة & الاولة \\
\hline $3 r \cdot 1$. & 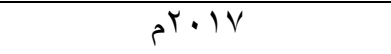 & $54+11$ & م) & م) & تاريخ الأصدار \\
\hline لا يوجد أصدار ات & 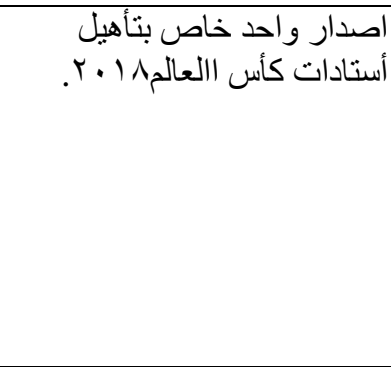 & 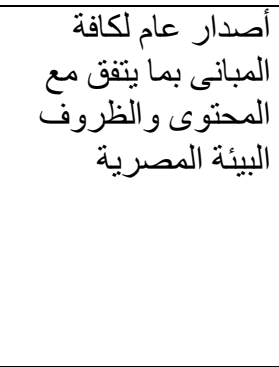 & 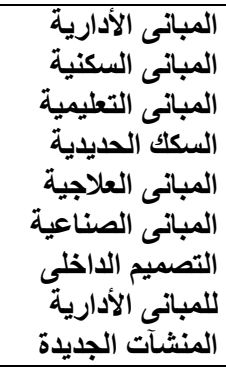 & 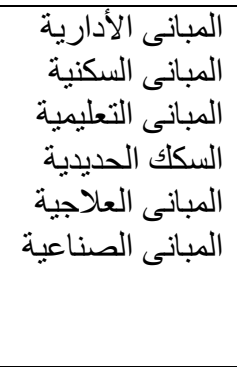 & أصدرات \\
\hline- & محلى & محلى & عالمى & عالمى & نطاق التطبيق \\
\hline
\end{tabular}


دليل تقييم أستدامة أستادات كرة القدم المصرية'

\begin{tabular}{|c|c|c|c|c|c|}
\hline الطاقة المتجددة & الدر اسات الأولية. & كفاءة أستهلاك طاقة & طاقة وغلاف جوى & الطاقة & محددات التقييم \\
\hline كفاءة المباه & الراحة وجودة البيئة الداخلية & كفاءة أستهلاك مياه & ترشيد المياه & المياة المياة & \\
\hline أُعادة التدوير & جودة العمارة وتنسيق الموقع. & جودة بيئة داخلية & جودة بيئة داخلية & صحة ورفاهية & \\
\hline الغذاء الصحي & الداخلية. & - & موقع ونقل & النقل & \\
\hline \multirow[t]{9}{*}{ أستخر أمانًا مو اد كيميائية } & و والتخلص من الصرف الصاياتى & مو اد وموارد & مو اردومو اد بناء & المواد & \\
\hline & الحفاظ على المياه & أبداع وقيم مضنافة & الأبداع & الأبداع & \\
\hline & مصدر الأمداد وكفاءة الطاقة & أستدامة و أيكولوجى & أستدامة موقع & ايكولوجية و أستعمال & \\
\hline & أستخدام الطاقة البديلة & أدارة & الأولوية الأقليمية & الأدارة & \\
\hline & وأعتبار ات البيئة و التطوير & - & - & التلوث & \\
\hline & الأداء الأقتصادى & - & - & مخلفات البناء & \\
\hline & جودة التصميم & & & & \\
\hline & IT & V & $\Lambda$ & 1. & عدد المحددات \\
\hline & جودة التشغيل & كفاءة أستهلاك المياه & الطاقة & الطاقة & العنصر الاهم \\
\hline لا نوجد شهادات تقييم & يقالنقاط شهادة أستدامة محلية باسم & 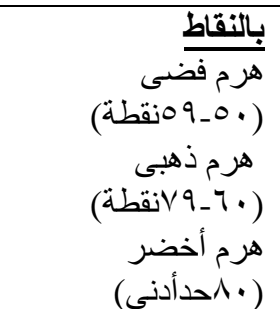 & 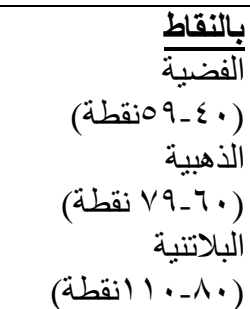 & 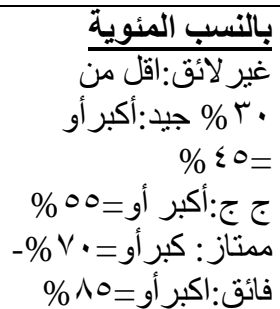 & أسلوب التقييم \\
\hline
\end{tabular}

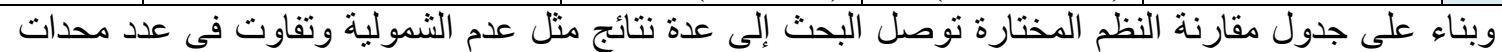

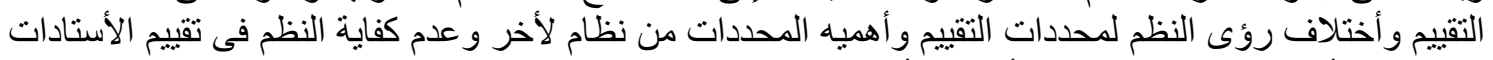
مما يبرر الأحتياج لبناء دليل جديد لأستدامة أستادات كرة القدم المحلية.

\section{ثالثا :بناء الدليل المقترح} • ماهيه اختيار محددات التقينيم

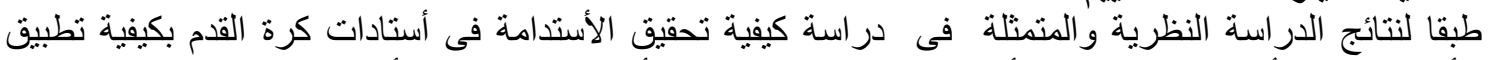

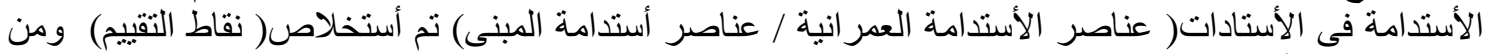

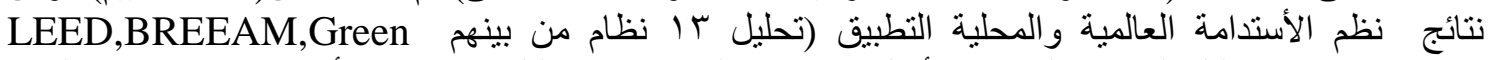

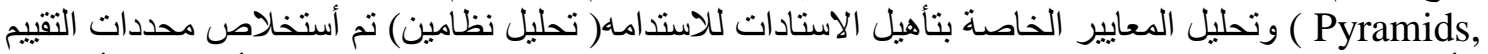

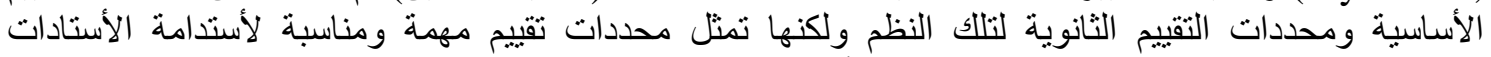

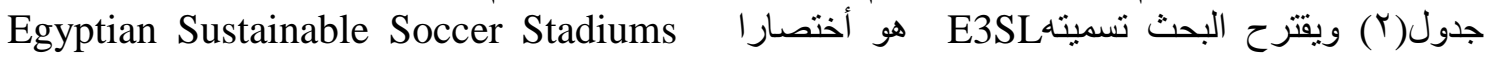
Leader Ship 


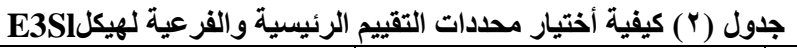

\begin{tabular}{|c|c|c|}
\hline هيكلE3SI المقترح & نتائج تحليل نظم الأستدامة & نتائج الفصل الأول \\
\hline محددات التقييم المستتنجة & محددات التقييم الرئيسية & نقاط التقيم \\
\hline ا -ترشيد أستهلاك الطاقة & \multirow[t]{3}{*}{ ا-ترشيد أستهلاك الطاقة } & التصميم السلبى \\
\hline التصميم السلبي & & التصميم الأيجابى \\
\hline التصميم الأيجابى & & مصدر متجدد للطاقة \\
\hline مصدر متجدد للطاقة & \multirow[t]{2}{*}{ r- ترشيد أستهلاك المياه } & ترشيد المياه داخل الأستاد \\
\hline r ـ ترشيد أستهلاك المياه & & ترشيد المياه فى الموقع العام \\
\hline ترشيد المياه داخل الأستاد & \multirow{3}{*}{ بـ ـ ترشيد المواد والموارد } & المواد المستخدمة \\
\hline ترشيد المباه فى الموقع العام & & كفاءة التصميم عمارة/أنشاء \\
\hline r-ترشيد مواد البناء والتشطيب & & أسلوب البناء \\
\hline مو اصفات المواد المستخدمة & \multirow{4}{*}{ ع -جودة البيئة الداخلية } & الحد من تلوث الهو اء \\
\hline جودة التصميم & & الر احة المناخية \\
\hline أسلوب البناء المستخدم & & الأضاءة الطبيعية والصناعية \\
\hline ـ ـجودة المناخ الاخلى & & بيئة صوتية مناسبة \\
\hline جودة الهواء الداخلى & \multirow[t]{2}{*}{ هـ_أستدامة الموقع } & أختيار الموقع المناسب \\
\hline الر احة الحرارية & & تنسيق الموقع العام \\
\hline الر احة البصرية & 7- الأبداع & - \\
\hline الر احة السمعية & محددات التقييم المناسبة & \\
\hline هـالأستامة العمر انية & V Vودة الخدمات & خذمة المجتمع و المستخدمين \\
\hline أختيار الموقع & 1ـ كفاءة النقل & كفاءة النقل و المو اصلات \\
\hline تتسيق الموقع العام & \multirow[t]{2}{*}{9 ـ التعامل مع المخلفات } & التعامل مع مخلفات البناء \\
\hline كفاءة النقل و المو اصلات & & التعامل مع مخلفات التشخيل \\
\hline \multirow[t]{3}{*}{ خدمة المجتمع والمستخدم } & \multirow[t]{3}{*}{ • اجودة التشغيل } & عناصر مبنى الأستاد \\
\hline & & نظم التشغيل و السلامة \\
\hline & & منطلبات ذوى احتياجات \\
\hline 7-الأبتكار & إلالأدارة & - \\
\hline V-التعامل مع المخلفات & r إلـ الأقتصاد & - \\
\hline التعامل مع مخلفات البناء & - & - \\
\hline التعامل مع مخلفات التشغيل & - & - \\
\hline 1_-جودة التشغيل & - & - \\
\hline جودة عناصر مبنى الأستاد & - & - \\
\hline جودة منطلبات ذوى احتياجات & & \\
\hline جودة نظم التشغيل و السلامة & - & - \\
\hline 9-الأدارة & - & - \\
\hline · ا ـتعزيز الموارد المالية & - & - \\
\hline
\end{tabular}

و وطبقا لجدول (r) تتلخص محددات التقييم فى دليل E3SL و عددها عشرة محددات أساسية فى:

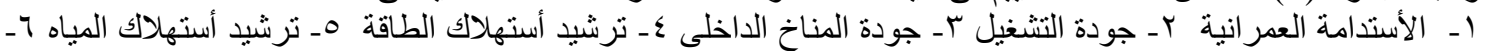

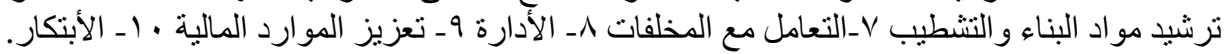




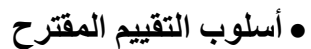
تبعا لتحليل نظم التقييم الأخضر كما بجدول (1) كان أسلوب التقييم بالنقاط التجميعية هو الأكثر أستخداما بين النظم وذلك بهدف تيسير عمليه التقييم تبعا لوجود منطلبات تفصيلية تحقق تلك النقاط التجميعية و حتى لا يكون التقييم تقديرى فلم يكن التقييم في صور فه نسب مئوية.

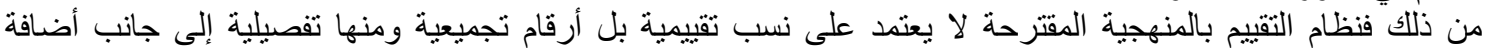

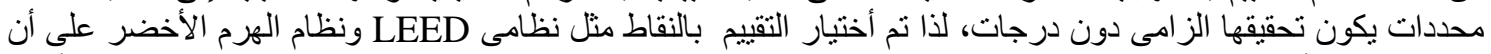

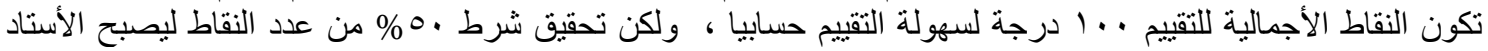
مستداما الفماط

• توزيع نقاط التقييم على المحددات المقترحة يخضع نسب توزيع نقاط التقييم وترتيب التئ محددات التقييم في دليل E3SL بما يلائم الوضع المحلى ويحد من مشكلات الأستادات

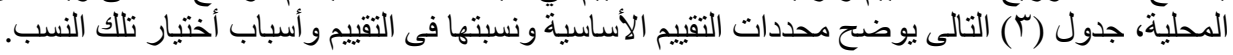

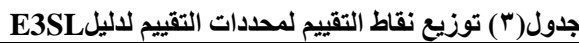

\begin{tabular}{|c|c|c|}
\hline أسباب نسبة تقييم المحدد الواحل & نسبة تقييم & محددات التقييم \\
\hline \multirow{2}{*}{ 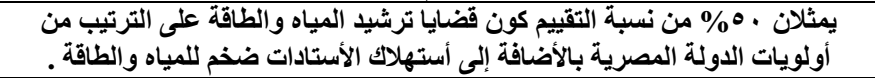 } & $\%$ \%. & ترشيد أستهلاك المياه \\
\hline & $\%$ \%. & ترشيد أستهلاك الطاقة \\
\hline لأهمية الحد من تكاليف الأنشاء فى ظل أرتفاع أسعار مواد البناء فى مصر . & $\%$ Ir & ترشيد مواد البناء والتشطيب \\
\hline \multirow{3}{*}{ تساوى المحددات الثلاثة فى أهمية توفيز متطظبات الراحة والأمن والسلامة لعناصر } & $\% \wedge$ & جودة التشغيل \\
\hline & $\% \wedge$ & جودة المناخ الداخلى \\
\hline & $\% \wedge$ & الأستـامة العمر انية \\
\hline 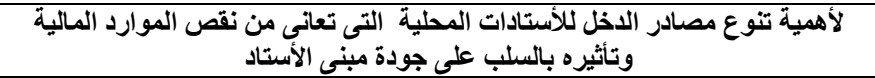 & $\% \mathrm{~V}$ & ت تعزيز الموارد المالية المية \\
\hline لأهمية الحد من مخلفات الأستاد الضخمة أثناء مرحلة البناء أو التثشغيل. & $\%$ & التعامل مع المخلفات \\
\hline أقلّل المحددات وزنا لإن دورها المتابعة والأشر اف على تحقيق أستدامة المبنى & $\% r$ & الأدارة \\
\hline تقييم الأبداع درجات أضافية لان مبنى الأستاد يمكن أن يكون مستداما بدون أى أضافات & 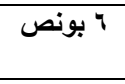 & الأبتكار \\
\hline
\end{tabular}

• أشتر اطات خاصة بعملية التقبيم

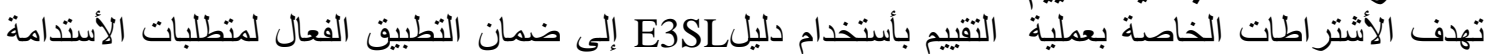

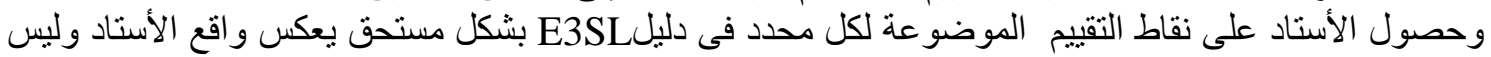
تطبيق شكلى و التى تتلخص فلى النقاط النقاط التالية: الدرجات الخاصة بتقيبم جودة التشغيل يحصل الأستاد عليها كاملا بشرط أستيفاء المنطلبات الخاصة بكل نقطة تقييم طبقا لأحدث أثنتر اطات الفيفا .

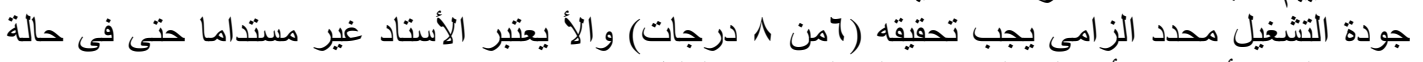

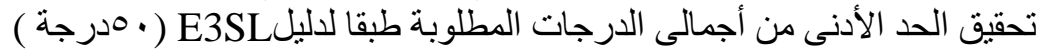

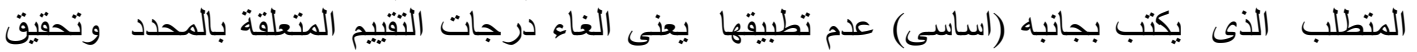

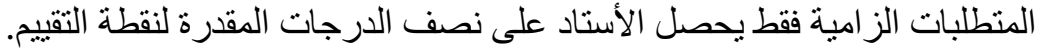
المنطلب الذى يكتب بجانبه (بونص) تزيد من درجات الأنساد التقييم الأستاد دون أجتياز الحد الأقصى من الدرجات

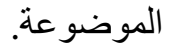
تقييم ترشيد الطاقة وترشيد المياة وترشيد مو اد البناء والتشطيب يتوقف حصول الأستاد على درجات التقبير

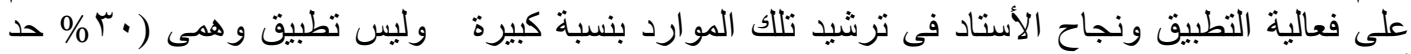

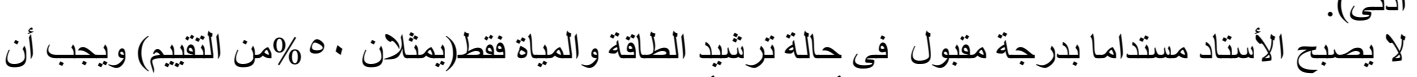
تغطى تلك النظم باقى المحددات ويستنثى الأبتكار و الأدارة.

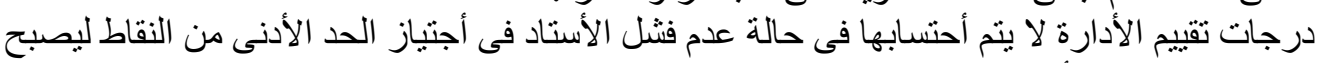

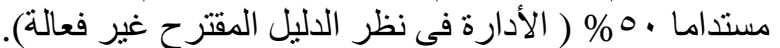

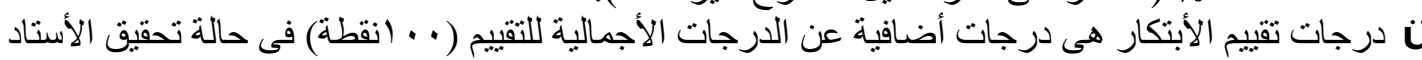
أضافة مميزة لتحقيق الأستدامة .

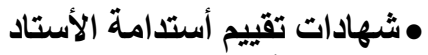

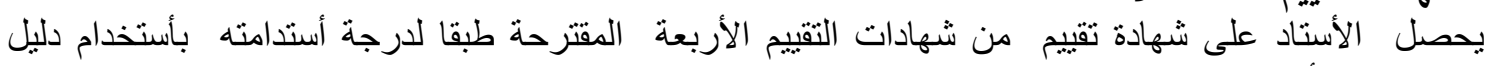
E3SL

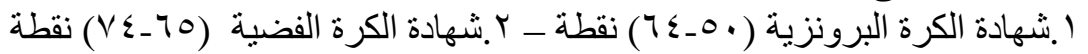

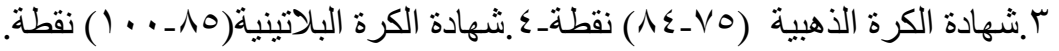


• • • • أشتراطات الحصول على شهادة أستدامة

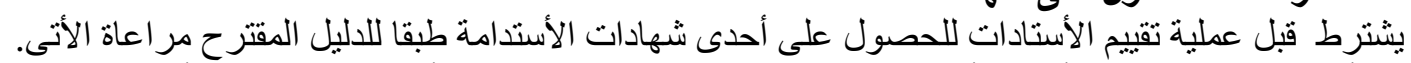

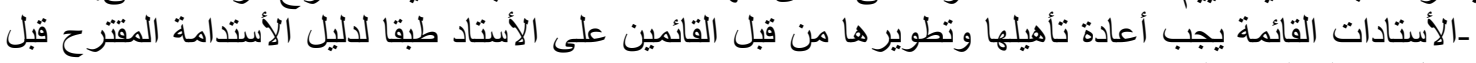

دخول مرحلة التقييم النهائية.

ـالأستادات الجديدة المصممة أو التى تم تطوير ها طبقا لدليل الإستدامة المقترح يجب الفئ أن يدخل حيز التشغيل فعليا

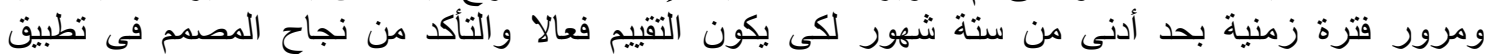

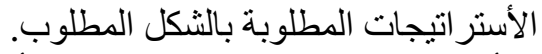
ـالأستادات التى تفشل فى عملية التقييم تأخذ مهلة زمنية بالتنسيق مع أدارة الأستاد ليعاد تقييمه.

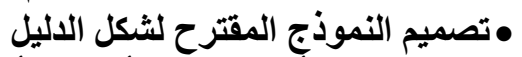

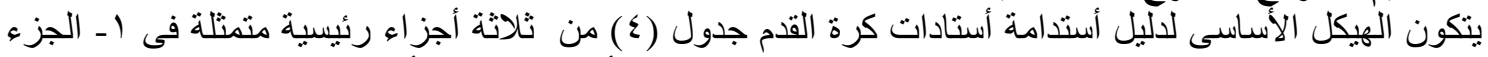

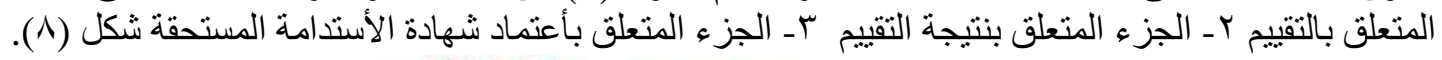

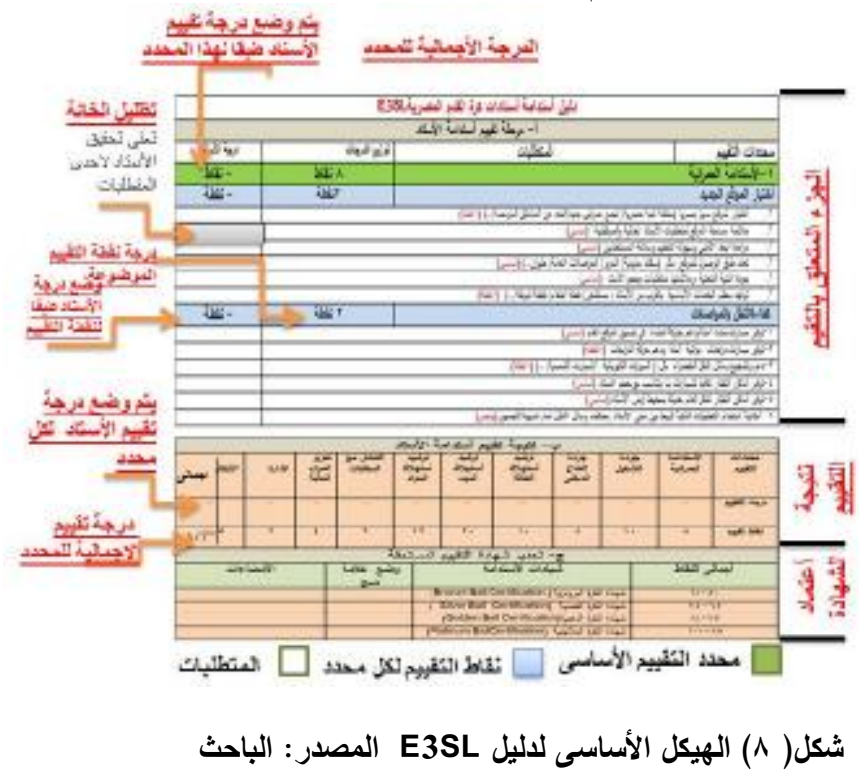


دليل تقبيم أستدامة أستادات كرة القدم المصرية'

\begin{tabular}{|c|c|c|}
\hline (..) نقاط & م نقاط & با -جودة المناخ الداخلى \\
\hline \multirow[t]{4}{*}{ ـ نقطة } & r نقطة & جودة الهواء الآاخلى \\
\hline & 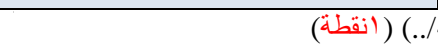 & اــأستخدام النظم الحديثة التى تحد أو تمنع التلوث(نظم قياس نسبة التلوث/ نظم سحب الهو اء/ نظم تجديد الهوا. \\
\hline & & r -أختبار مو اد التشطيب الخضر اء الصديقة للبيئة و الإنسان (أساسى) \\
\hline & & rا-منع التندين داخل الفر اغات المغلقة أو داخل المدرجات وتخصيص أماكن مخصصة للتنخين ( انقطة) \\
\hline \multirow[t]{6}{*}{ ـ نقطة } & 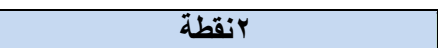 & الراحة الحرارية \\
\hline & سيق الموقع/..) ( انقطة) & ا-تطبيق فعال للمعالجات المعمارية لتقليل الحمل الحرارى (توجيه/ العزل الحر ارى/ زراعة الأسطح/المواد/ت \\
\hline & ت/اتغطية المدرجات فقط/..) (أساسى) & rـ التهوية الطبيعية للمدرجات ( أستخدام تقنبة الواجهات ذات الوحدات المتحركة فى التهوية الطبيعية للفر اغا \\
\hline & & r-أستخدام النظم الميكانيكية ( نظم التبريد / نظم التسخين) الذكية لضبط درجة الحر ارة والرطوبة ( (نقطة) \\
\hline & & ـ ــاستخدام الأسقف المتحركة لتوفير أعلى مستوى من الراحة والأمان لعناصر اللعبة (بونص) \\
\hline & & هـتغطية المدرجات على الأقل للحماية من الأشعاع الثمسي أو تغطية الأستاد بالكامل إن تتطلب الامر (أن \\
\hline \multirow[t]{4}{*}{ ـ ـ نقطة } & r نقطة & الراحة السمعية \\
\hline & & ا ـ-معالجة الضوضاء و الحد من تأثير اته بالطريقة المناسبة ( انقطة) \\
\hline & & r-تصميم النظام الصوتى المناسب طبقا لنو عية ومستوى الأستاد لتحقق جوده السمع (اساسى) \\
\hline & & r بـ تصميم النظام الصوئى يلائم الأستخدامات غير الرياضية (انقطة) \\
\hline \multirow[t]{5}{*}{ - نقطة } & r بقطة & الراحة البصرية \\
\hline & & اـ الأضاءة الطبيعية لمبني الأستاد نهار ا مع مر اعاة منع حالة الابهار و الز غلله بالوسائل المناسبة (أساسى) \\
\hline & & r-تصميم الأضاءة الصناعية للفر اغات الداخلية بالثكل المناسب (الأستخدام الليلي) ( انقطة) \\
\hline & & ب-تصميم الأضاءة الصناعية لأنارة الملعب طبقا لأشتر اطات الفيفا (الأستخدام اللبلي) (أساسى) \\
\hline & & ـ ـ-مر اعاة البعد الجمالي في تصميم الأستاد وأختبار مو اد التشطيب الداخلية والخارجية المناسبة (انقطة) \\
\hline (..) & 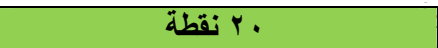 & ع - ترشيا أستهلاك الطاقة \\
\hline \multirow[t]{5}{*}{ - نقطة } & 7 1 & الأعتماد على التصميم السالب \\
\hline & عدم تغطية المدرجات / تغطية متحركة/..) & ( آنقطة) \\
\hline & لحجم الفراغ/الواجهات النافذة للضوء فقط & (انقطة) \\
\hline & التوجيه المناسب/..) (كنقطة) & كـالتهوية الطبيعة المناسبة لمدرجات الأستاد ( عدم تغطية المدرجات نهائيا/ التصميم المناسب تغطية الأستاد / \\
\hline & 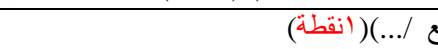 & ـ ـالتهوية الطبيعية للفر اغات الداخلية ( التوجيه المناسب/ تصميم الفتحات لحجم الفر اغ/التنسيق المدروس الموف \\
\hline \multirow[t]{8}{*}{ - نقاط } & أنقاط & الأعتماد على التصميم الموجب \\
\hline & 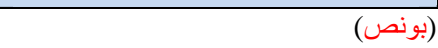 & ـ ـأستخدام تقنية(تحويل الطاقة الحركية إلى طاقة كهربائية ) مثل (مسارات الحركة الأفقية / السلالم المتحركة) \\
\hline & & r بأستخدام عناصر أنارة حديثة موفرة للطاقة (الأنارة (LED)/ الأضاءة بالأستشعار /.) (rنقطة) \\
\hline & & ب-تصميم الأضاءة الصناعية لأرض الملعب بشكل يقلل أستهلاك الطاقة ( (نقطة) \\
\hline & & ع ـاستخدام نظم تشغيل ذكية موفرة للطاقة ( (نقطة) \\
\hline & & هـأستخدام نظم ادارة الطاقة المبرمجة BMS \\
\hline & & آـأعادة أستغلال الحر ارة المفقودة من بعض نظم التشغيل وأعادة أستخدامها فى التنخين أو التدفئة ( (نقطة) \\
\hline & لماقة(أساسى) & V-الأهتمام بالصبانة المطلوبة لنظم التشغيل المختلفة لترشيد أستهلاك الطاقة و المر اقبة المستمرة للأستهلاك الد \\
\hline \multirow[t]{4}{*}{ 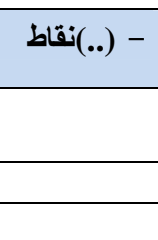 } & ع نقاط & الأعتماد على مصدر متجدد للطاقة \\
\hline & خوئية فى التغطيات و الو اجهات/ ...) لتوفير & أحتباحتماد مالإستاد على مصاقدر أو أكثر من مصادر الطاقة المتجددة مثل الطاقة الثمسية (أستخدام خلايا الكهرو \\
\hline & & r ـ أستخدام سخانات شمسية بديلا للسخانات الكهربائية لاغر اض التسخين( ؟ نقطة) \\
\hline & & r - الاهتمام بالصيانة المطلوبة عناصر نوليد الطاقة المتجددة(الخلايا الكهروضوئية / توربين الرياح/...) (أساس \\
\hline (..) & 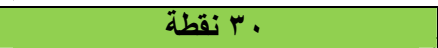 & • - ترشيد أستهلاك المياه \\
\hline \multirow{5}{*}{ 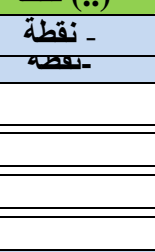 } & 10 & ترشيد المياه في الموقع العام للأستاد \\
\hline & مفتوحة (بنقاط) & ا ـأختبار النباتات المحلية قليلة الأستهلالك للمياه أو أستبعادها أو أستخدام عشب صناعى فى تتسيق الفراغات || \\
\hline & & بـ-أستخدام نظم رى موفرة للماء مثل نظام الرى الأوتوماتيك (r نقاط) \\
\hline & & بَ-زر اعة أسطح المبانى الملحقة بالأستاد أو سقف المدرجات (َ نقاط) \\
\hline & & ـ ـعمل خز انات تجميع مياه الأمطار و أعادة أستخدامها فى أعمال الرى (أساسى فى المحافظات الممطرة ) ("ان \\
\hline \multirow[t]{2}{*}{ طं - } & بها (بنقاط) & ه_عمل نظام صرف مناسب(رصف منفذ للمباه /..)و أختبار نظام مناسب لمعالجة المياة الرمادية وأعادة استخدا \\
\hline & 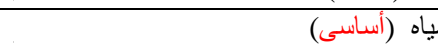 & آـالأهتمام بأجر اء الصبانة الدورية لكافة التوصيلات الصحية وشبكات الرى وتركيب أجززة كثف تسريب الا \\
\hline \multirow[t]{5}{*}{ ـ ـ تقطة } & هانقطة & ترشيد المياه داخل مبنى الأستاد \\
\hline & و أدو اش متدفقة بالأستشعار / مر احيض ذوق & ا ـأستخدام الأجهزة الصحية الحديثة الموفرة للمياه ( المباول الجافة/ صنابير و ادو اش ضعيفة التدفق / صنابير \\
\hline & & صندوق الطرد المزدوج/معدات غسل الأو انى بالبخار/..) (†نقاط) \\
\hline & & r-عمل شبكة لتدوير المباه وأعادة أستخدامها فى أغر اض النظافة وتغذية الأجهزة الصحية ونظم التبريد (بنق \\
\hline & & آ ـأستخدام نظم تحكم حديثة و فعالة لتنظيم حركة الجمهور (البو ابات الأكترونية/..) (أساسى) \\
\hline
\end{tabular}




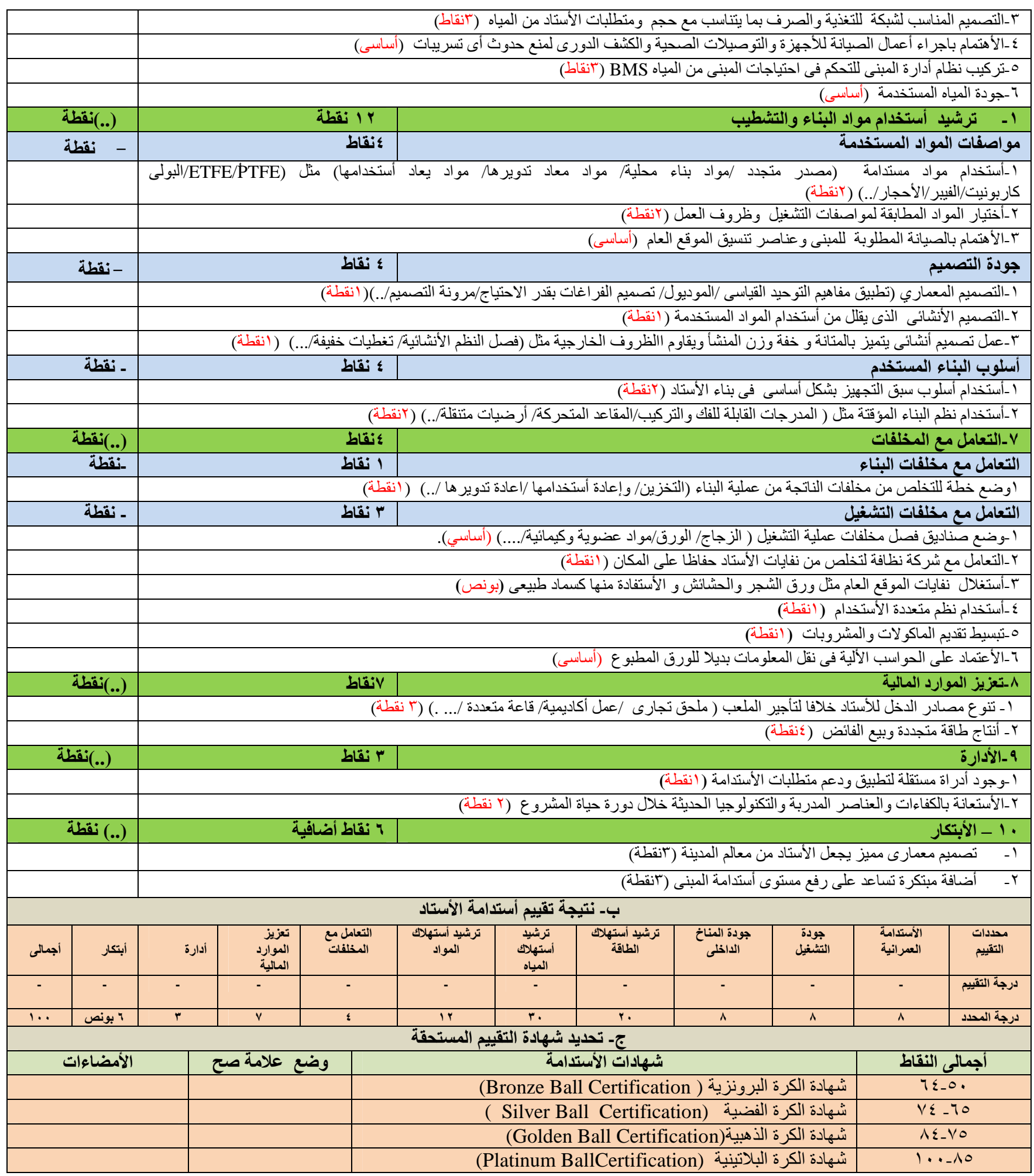

\section{رابعا :نتائج البحث}

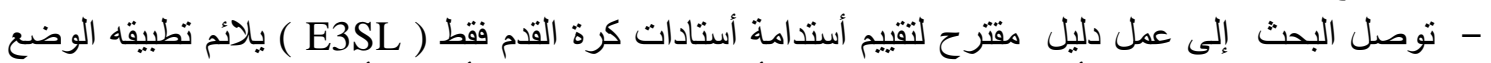

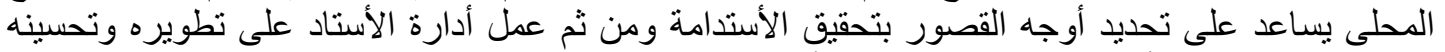
طبقا لمنطلبات دليل الأستدامة المقتر ح لتحقيق الأستدامة المطلوبة. 
- من خلال أستبيان رأى (شريحة شملت 0 ه شخصا من المختصين وأكاديمين)لاقى هذا الدليل أهمية

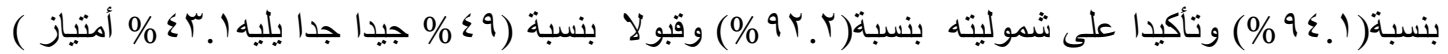

شكل (9). (1).

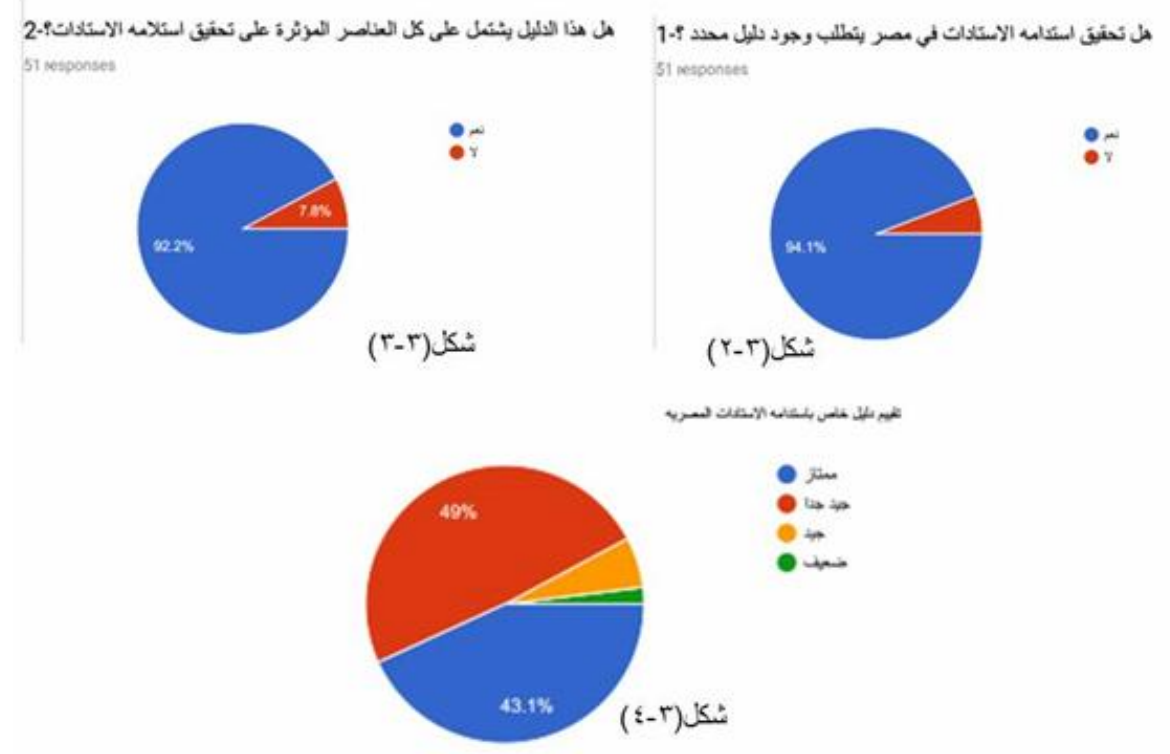

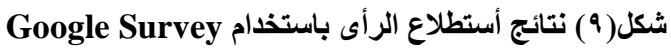

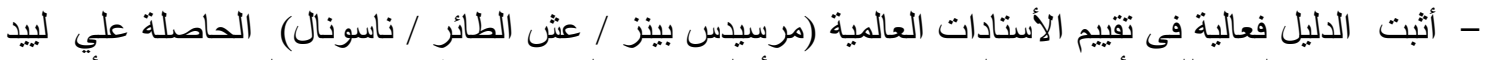

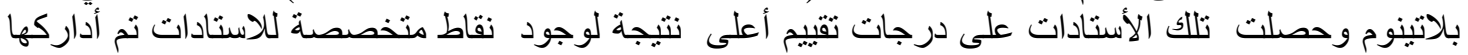

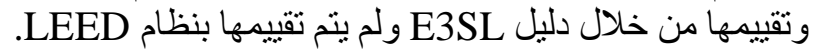

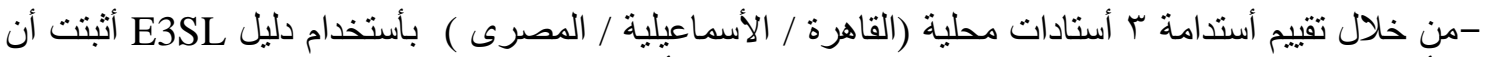

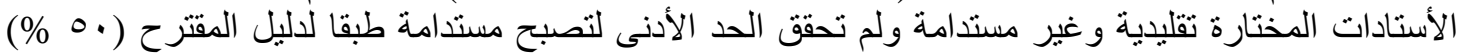

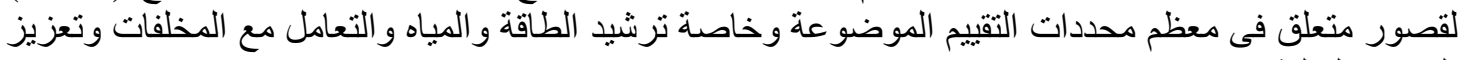

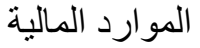

ع ـالتوصيات

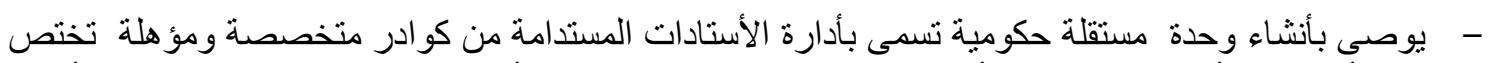

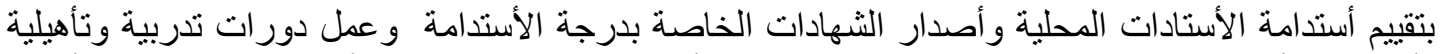

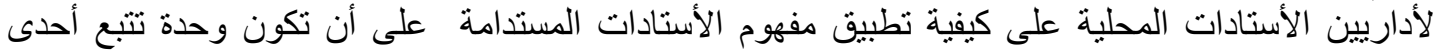
الوزر ات المعنية ويفضل أن تكون وزرارة الارة البيئة.

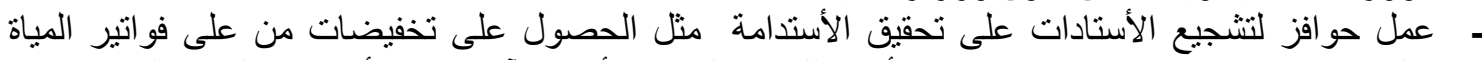

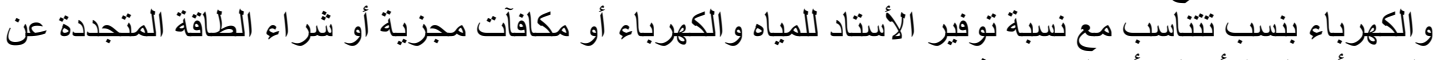
فائض أحتياج الأستاد بأسعار مغرية. - - دراسه منشآت رياضية أخرى غبر أستادات كره القدم من أجل تحقبقها الأستدامة.

1. Casbee For Building (New Construction,2014).

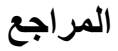

Http://Www.Ibec.Or.Jp/CASBEE/English/

2. Owen E.,2009,"Sustainable Landscaping For Dummies", Indiana, Wiley Publishing Inc.

3. U.S.Green Building Council,USA,2018, Guide LEED V4 Edition.

4. UEFA,2011," GUIDE TO QUALITY STADIUMS".

5.BRE,2018,BREEAM, Www.BREEAM.COM.

6. Www.Ccsenet.Org $>$ Isd $>$ Article>Download. 
7. Www.Twgbqanda.Com.

8. FIFA, ,2011 , "Football Stadiums Technical Recommendations And Requirements" ${ }^{\text {th }}$ Edition.

9. France GBC,2015,"International Environmental Certifications For The Design And Construction Of Non-Residential Buildings".

Https://Www.Worldgbc.Org/Country/France

10. Green Globes Rating System,2000 ,Http://Greenglobes.Com.

11. Indian Green Building Council, IGBC Ratig System ,Https://Igbc.In/Igbc.

12. Green Building Council Of Australia.2002,"Green Star Rating System" Https://New.Gbca.Org.Au/Green-Star/.

13. Https://Www.Dgnb-System.De/En/Index.Php.

14. Ileana Q, Nawari O. Nawari,2015" Sustainable Design Strategies For Sport Stadia", University Of Flourda, Volume3,(Issue1),P13,P18

15.Http://Openarc.Co.Za/Sites/Default/Files/Attachments/SBAT\%20manual.Pdf

Geriant J, Rod S\& Ben V,2007,"Stadia",Oxforde, Elsevier .

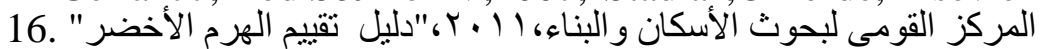

